\title{
REGIMES POLÍtICOS E POTENTIA: A REVIRAVOLTA ESPINOSANA
}

\author{
Luiz Carlos Montans Braga ${ }^{1}$ \\ Pontifícia Universidade Católica de São Paulo (PUCSP) \\ (D) https://orcid.org/0000-0002-6989-1249
}

\section{RESUMO:}

O tema de fundo do artigo é o dos regimes políticos em Espinosa. O objetivo é o de analisar, no interior deste tema mais amplo, o da distribuição da potência entre os membros do corpo político como critério comum aos regimes. A questão dos regimes, em Espinosa, não passa apenas pela definição do número dos que governam. Um rol de conceitos - homem como potência, afetos, multidão, imperium, entre outros - deve ser levado em conta para tratar da clássica questão.

PALAVRAS-CHAVE: regimes políticos; potentia; afetos; multitudo; Espinosa.

\section{POLITICAL REGIMES AND POTENTIA: THE SPINOZIAN TWIST}

\begin{abstract}
:
The background theme of the article is the political regimes in Spinoza. The aim is to analyze, within that broader theme, the distribution of power among the members of the political body as a common theme about the regimes. The question of the political regimes in Spinoza is not only about the number of governors. A list of concepts - like man as potentia, affects, multitudo, imperium, among others - must be taken into account to address the classic question.
\end{abstract}

KEYWORDS: political regimes; potentia; affects; multitudo; Spinoza.

\footnotetext{
${ }^{1}$ Doutor em Filosofia pela Pontifícia Universidade Católica de São Paulo (PUC/ SP), São Paulo - Brasil. E-mail: montansbraga@ hotmail.com

Regimes políticos e potentia: a reviravolta espinosana - Luiz Carlos Montans Braga
} 


\section{Esboço de alguns conceitos espinosanos fundamentais ao tema}

Espinosa trata da questão da fundação do campo político, bem como da sua manutenção ao longo do tempo, por meio da articulação sui generis de alguns conceitos peculiares à sua obra, especialmente aqueles presentes na Ética, no Tratado Teológico-político e no Tratado Político ${ }^{2}$. Tais conceitos são os seguintes: homem como intensidade de potência (modificação da substância única, isto é, modo do pensamento e modo da extensão, ambos expressões da potência de Deus, ou seja, da substância única), afetos, imitação afetiva, direito como potência, multidão, tensão entre poder soberano e multidão, imperium, cidade.

A imitação afetiva faz que os desejos em dispersão se espelhem uns nos outros e formem desejos-em-conjunto, o que pode ser compreendido como blocos de mentes orientadas, levando à prática de ações neste ou naquele sentido por parte dos homens.

A socialidade, em Espinosa, não se funda na racionalidade dos homens, isto é, no uso exclusivo da razão. Não há um cálculo eminentemente cognitivo para a criação de laços de cooperação entre os humanos, nem para a fundação da cidade por meio de um contrato resultante de vontades livres.

É a lei do bem maior entre dois bens e do mal menor entre dois males o critério da formação dos laços. E o fiel da balança é sempre a satisfação do desejo de cada homem, o exercício de sua potência (ou seja, de seu direito natural) de modo real. Porém, surge a questão: como orientar num sentido comum desejos dispersos? Uma razão de fundo, ou astúcia da razão (CHAUI, 2011, p. 182), é o que se manifesta entre os homens quando a esperança vence o medo - afetos, portanto - e a segurança vence o

\footnotetext{
${ }^{2}$ As obras de Espinosa que serão mencionadas se encontram na edição crítica de Carl Gebhardt (ESPINOSA. Spinoza Opera. Ed. de Carl Gebhardt. Heidelberg: Carl Winter, 4 vols, 1972 [1 $1^{\text {a }}$ ed. 1925]). Quando citada a edição de Gebhardt, citar-se-á: G, seguido do tomo em romano e da página em arábico. As traduções consultadas são as seguintes: ESPINOSA. Ética. Tradução de Tomaz Tadeu. Belo Horizonte: Autêntica, 2008. ESPINOSA. Tratado Político. Tradução, introdução e notas de Diogo Pires Aurélio. São Paulo: M. Fontes, 2009. ESPINOSA. Tratado Teológico-político. Tradução, introdução e notas de Diogo Pires Aurélio. São Paulo: Martins Fontes, 2003. Para a E e o TP, usar-se-á a seguinte abreviação: para a Ética E, seguido da parte em romano, D para definições, Def af para definição dos afetos, A para axiomas, Dem para demonstrações, P para proposições, Cor para corolários, Ap para apêndices, L para lemas, Esc para escólios, Post para postulados, Explic para explicações. Um numeral arábico indicará o número de cada um desses itens. Após, a página em arábico. Para o TP, numeral romano indica o capítulo e numeral arábico indica o parágrafo. Após, a página em arábico. Para o TTP, numeral romano indica o capítulo. Após, a página em arábico. Assim se procede para facilitar a consulta a qualquer edição das obras de Espinosa, mesmo que seja à custa do não cumprimento estrito das regras de citação da ABNT.
} 
desespero. Com efeito, se todos os homens agissem com o uso exclusivo da razão, não haveria necessidade da política para forjar acordos, segundo o autor, pois os homens já estariam em acordo pelo uso da razão (E IV P 37 Esc 2 p. 309 e P 35 Cor 1 p. 303). A astúcia da razão, uma razão com 'r' minúsculo, se apresenta, segundo a hipótese de CHAUI (2011, p. 182), pela predominância de tais afetos alegres na cidade (esperança e principalmente sua fixação em forma de segurança). Isso é o que o desejo busca, e o faz por imitação afetiva, pois apenas assim o direito natural, como potência que é (jus sive potentia - TP II 5 p. 12; G III p. 277), poderá se realizar como algo efetivo, real, não como abstração (TP II 15 p. 19).

Ora, para que isso ocorra, é preciso que a dispersão de desejos, por meio da lei do bem maior e do mal menor, bem como da imitação dos afetos, venha a ser multidão (multitudo), isto é, desejos alinhados no sentido do comum. Essa mesma multidão transfere potência (direito) ao poder soberano para que este dê à cidade e seus membros suas leis. Tais leis também se sustentam pela potência da multidão. Por isso as leis da cidade, criadas pelo poder soberano, devem forjar um imaginário nas mentes dos homens que seja de futuro-em-forma-de-esperança-e-segurança, ou seja, manifestações de afetos alegres (a segurança é a esperança da qual se afastou a dúvida; o desespero, ao invés, é o medo do qual se afastou a dúvida - E III Def af 14 e 15 p. 245). Caso as leis forjadas pelo soberano não sejam capazes de criar este imaginário nas mentes dos homens, elas perdem potência e a cidade pode se dissolver. A tensão positiva (porque mantém a cidade como tal) poder soberano versus multidão vem a ser, neste caso, conflito. Aí passam a existir desejos em confronto, direitos naturais em contraste. Portanto, potência em torno de um grau zero em cada homem, direitos naturais como abstração (TP II 15 p. 19), dispersão da cidade, fim da positividade da tensão multidão versus poder soberano e união, por meio do afeto indignação em face do soberano, da multidão, o que leva ao fim do corpo político. Trata-se, neste caso, da morte de um específico corpo político.

Portanto, a fundação e manutenção do campo político em Espinosa se dão ao longo do tempo, afetivamente, e não em um momento, por meio do uso da razão e da vontade livre (MONTANS BRAGA, 2015; CAMPOS, 2008).

Esse brevíssimo esboço ${ }^{3}$ permite aqui pontuar - e apenas pontuar, pois o tema em que se mergulhará vem a seguir e demanda esta reconfiguração conceitual - que Espinosa apresenta uma filosofia política que rompe tanto com a tradição filosófica de seu tempo quanto com a anterior, tema que não será objeto do presente artigo. Não há, com efeito, no

\footnotetext{
${ }^{3}$ Para aprofundar o tema da criação e manutenção do campo político em Espinosa, remeto à minha tese de doutorado (MONTANS BRAGA, 2015), especialmente ao Capítulo 2, item (c). Lá há vasta bibliografia sobre o tema.
} 
"contratualismo" espinosano homens dotados de vontade livre, momento fundador definitivo, que não mais se realiza no tempo, bem como cálculo racional instrumental medindo meios e fins para a decisão política fundadora. Se uma racionalidade há, ela se mostra de viés, na hipótese da astúcia da razão (CHAUI, 2011, p. 182), pelos afetos e pela lei do bem maior e do mal menor. Assim, mesmo para as análises contemporâneas acerca da política, os conceitos espinosanos se apresentam muito inovadores. A inserção dos conceitos de afeto, imitação afetiva, direito como potência e multidão como fundadores e instituintes constantes do campo político leva, segundo a interpretação aqui proposta acerca de Espinosa, à solução da questão do fundamento da cidade. Mas não apenas. Abre horizontes de alta voltagem conceitual para as discussões políticas e jurídicas contemporâneas. A análise e aprofundamento das ideias lançadas neste parágrafo ficam, entretanto, para outra ocasião.

O desenho conceitual acima apontado servirá como pano de fundo para o aprofundamento do tema mesmo do artigo, indicado a seguir.

\section{Os regimes políticos segundo o critério da potentia}

O objetivo do artigo é tratar especificamente da questão dos regimes políticos pela pena de Espinosa. Se o campo político, sua fundação e equilíbrio no decorrer do tempo, é decorrência da articulação dos conceitos espinosanos acima apontados, também na questão dos regimes políticos há inovação.

Trata-se de analisar, daqui em diante, uma questão clássica da filosofia política pela pena de Espinosa, a saber, a questão dos regimes políticos. Ou, para usar os termos do autor, a questão dos gêneros de estado civil. Porém, focando um tema daí decorrente, a saber, a questão da distribuição da potentia como critério comum à análise dos regimes.

Novamente, em Espinosa, na medida em que todo o rol conceitual foi modificado, o que existe é, também neste ponto, o que se poderia chamar de uma reformulação conceitual (CAMPOS, 2008, p. 17 e sgtes). Esta reformulação, é claro, decorre dos conceitos acima analisados. Procurar-seá, a seguir, articular os conceitos, acima apontados em panorama, com a proposta espinosana para a solução da questão seguinte: as maneiras pelas quais a potência da multidão se organiza em formas de estado civil e segundo quais critérios.

O final do capítulo I do Político (TP I 7 p. 10) anuncia uma tese que está diretamente de acordo com a Ética III. Espinosa afirma nesta ocasião, em primeiro lugar, que os homens, onde quer que se juntem, formam costumes e um estado civil. Em segundo lugar, no mesmo parágrafo, afirma que as causas e fundamentos do imperium (ou estado, em tradução precária) não decorrem de ensinamentos da razão. Devem "[...] deduzir-se da natureza ou condição comum dos homens [ex hominum communi natura seu 
conditione deducenda sunt]." (TP I 7 p. 10; G III p. 276). A condição comum dos homens, ou a antropologia espinosana, está desenvolvida na Ética III, momento em que o autor trata da origem e da natureza dos afetos.

A condição comum dos homens é sua dinâmica afetiva. Não casualmente, no Político, Espinosa explicita, já nas primeiras linhas do capítulo I, esta condição comum, ao afirmar que a afetividade ou o estar sob os afetos é próprio dos homens. Como da imitação afetiva decorre a multidão e o imperium?

Isto é o que Espinosa descreve como projeto a ser desdobrado no capítulo seguinte à afirmação acima indicada, do final do capítulo I, e o capítulo II do Político tratará, de início, do tema apontado. A questão que se apresenta, pois, é a de saber como se constitui e se mantém o imperium ${ }^{4}$. Afinal, como aponta o texto do Político (TP I 7 p. 10), os homens formam costumes e estados civis.

O conceito de mimese afetiva será utilizado por Espinosa para explicar esta união de homens, sem que o conceito, porém, seja explicitado, no Político, tal qual fora na Ética III. Procurar-se-á extraí-lo do texto do TP. Isto porque os afetos fundam a política e a mantêm (MONTANS BRAGA, $2015)^{5}$. Um importante parágrafo em que o conceito de afetividade - e mais especificamente de imitação - está pressuposto nas análises espinosanas é o de número 10 do capítulo 2 do Político:

\begin{abstract}
Tem um outro sob seu poder quem o detém amarrado, ou quem lhe tirou as armas e os meios de se defender ou de se evadir, quem lhe incutiu medo ou quem, mediante um benefício, o vinculou de tal maneira a si que ele prefere fazer-lhe a vontade a fazer a sua, e viver segundo o parecer dele a viver segundo o seu. Quem tem um outro em seu poder sob a primeira ou a segunda destas formas, detém só o corpo dele, não a mente; mas quem o tem sob a terceira ou a quarta forma fez juridicamente seus [sui juris fecit (G III p. 280)], tanto a mente como o corpo dele, embora só enquanto dura o medo ou a esperança; na verdade, desaparecida esta ou aquela, o outro fica sob jurisdição de si próprio. (TP II 10 p. 17).
\end{abstract}

Espinosa trata, no referido parágrafo, de potência, ou seja, de estar sui juris ou alterius juris (sob sua própria jurisdição ou sob a jurisdição de outrem, respectivamente), como afirma em passagem anterior ao parágrafo citado (TP II 9 p. 16). O que está em jogo é estar sob a potência - ou seja, sob o direito - de si mesmo ou sob a potência de outrem, uma vez que jus

\footnotetext{
${ }^{4} \mathrm{O}$ imperium é conceito comumente traduzido por Estado ou estado. Optou-se por manter o termo em latim, pois se trata de algo diverso do conceito de estado. Para dizer de modo simples e direto: trata-se do direito definido pela potência da multidão (TP II 17 p. 20). A cidade, por sua vez, pode ser definida como corpo inteiro do imperium (TP III 1 p. 25). Esse ponto poderia ser objeto de artigo à parte.

${ }^{5}$ Para referências bibliográficas, consultar o Capítulo 2 da tese, bem como a Bibliografia ao final da tese.
} 
sive potentia (TP II 5 p. 12 - G III p. 277). Dois casos dão ao detentor do direito o corpo do outro. São os dois primeiros, em que o outro está sob o poder daquele que o amarrou ou daquele que tirou os meios de se defender ou de fugir. Detém, entretanto, o corpo $e$ a mente de um homem aquele que incute neste o medo ou, mediante um benefício, faz que este prefira abrir mão do próprio desejo imediato para ter acesso a um bem maior. Aquela lei indicada no Teológico-político, tão firmemente inscrita nos homens, (TTP XVI p. 237), e repetida na Ética IV (E IV P 37 Esc 2 p. 311), segundo a qual entre dois bens se escolhe o maior e entre dos males o menor, é o que Espinosa aponta neste excerto. E tal poder sobre um outro, fundado nesta lei, opera a mesma lógica já apontada no TTP e na Ética, isto é, a do afeto medo-esperança fundando o 'estar sob', ou seja, fundando o ato de estar sob jurisdição de outrem. Desaparecida a esperança que funda a obediência ao poder de outrem, ou desaparecido o medo, desaparece o direito do outro sobre a mente e corpo deste ou daquele homem. Cada homem volta, assim, a estar sui juris, ou seja, num estado pré-civil ou de natureza, no qual os direitos naturais são abstrações (TP II 15 p. 19).

As concessões quanto ao direito natural (iure suo naturali cedant - E IV P 37 Esc 2 p. 309), de que fala Espinosa na Ética IV, fazem parte da mesma lógica acima apontada. Ao fazer, num momento na história e cotidianamente, a cessão do direito natural ao poder soberano, na esperança de garantir a existência mesma do direito natural, cada homem transfere potência ao poder soberano, dá a esta instância poder para fazer que as leis por ele editadas sejam cumpridas. Ou seja, cada membro da cidade, em parte - pois não se cede toda a potência (TTP XVII p. 250) -, passa a estar sob a jurisdição (sui juris) do poder soberano, sob sua potência. Há, ontologicamente fundada, uma tensão entre potências. O soberano, de acordo com a lógica exposta no excerto citado (TP II 10 p. 17), detém mais poder que cada membro da cidade isoladamente na medida em que pode, por ameaças, fazer cumprir as leis. Mas este é apenas um lado da moeda, pois os membros da cidade cumprem a lei também na esperança de que todos a cumpram, inclusive o próprio poder soberano, garantindo-se a paz no corpo social. Quando Espinosa afirma que alguém - ou algo - tem sobre outrem poder, sublinha, no caso do poder sobre a mente e o corpo, que são os afetos esperança e medo que garantem tal relação. E esta relação cessa findos o medo e a esperança. Ou seja, os membros da cidade, por, simultaneamente, temerem e esperarem garantias do poder soberano da cidade, mantêm uma relação de submissão ao soberano que é, ao mesmo tempo e paradoxalmente, sua (dos membros da cidade) garantia de exercício da potência enquanto indivíduos, isto é, enquanto homens. Entretanto, tratase aqui do medo da lei (CHAUI, 2011 P. 173-191; p. 174 especialmente), não do medo animal anterior a qualquer instituição. Um medo que é possibilitador, paradoxalmente, da alegria e da potência dos membros da cidade (AURÉLIO, 2000, p. 334). Por outro lado, o poder soberano somente 
subsiste enquanto tem como fundamento de sua potência a própria potência dos desejos dos membros da cidade, sob a forma de multidão, a qual alimenta o poder soberano, sem a qual o poder soberano não possui qualquer potência, ou seja, qualquer direito. Por isso Espinosa poderá dizer, acerca do imperium monárquico, por exemplo, a título de conclusão do capítulo VII do Político, "[...] que a multidão pode conservar sob um rei uma liberdade bastante ampla, desde que consiga que a potência do rei seja determinada somente pela potência da mesma multidão e mantida sob a guarda desta." E conclui (TP VII 31 p. 85): "Foi esta a única regra que segui ao lançar os fundamentos do estado [imperium] monárquico."

Porém, como os desejos, a princípio isolados e tumultuadamente contrários uns aos outros, como afirmado em E IV P 37 Esc 2 (p. 309), devêm multidão? A hipótese deste artigo vai pelo seguinte veio: a mimese dos afetos esperança e medo, por parte dos membros da cidade em face do poder soberano, será o conceito necessário para que se entenda a passagem do Político que complementa o excerto do parágrafo 10 do capítulo II (TP II 10 p. 17) e que pode ser uma chave para a compreensão desta transformação. A passagem é a seguinte (TP II 13 p. 18): "Se dois se põem de acordo e juntam forças, juntos podem mais, e consequentemente têm mais direito sobre a natureza do que cada um deles sozinho; e quanto mais assim estreitarem relações, mais direito terão todos juntos." Analisa-se, a seguir, esta passagem à luz do excerto acima citado (TP II 10 p. 17). O objetivo é mostrar como surge aí o conceito de afeto e, mais precisamente, a necessidade da ideia de imitar o afeto do outro para que tal união subsista.

$\mathrm{O}$ acordo somente ocorre, de forma completa, segundo Espinosa, com o uso da razão (E IV P 37 Esc 2 p. 309 e P 35 Cor 1 p. 303). Mas os homens raramente a usam, e estão submetidos aos afetos, que os põem em divergência (E IV P 37 Esc 2 p. 309). Porém, não obstante estarem em desacordo, simultaneamente sabem que "[...] o homem é um Deus para o homem." (E IV P 35 Esc p. 303), e por isso a experiência mostra que dificilmente os homens vivem uma vida solitária, e em geral vivem em sociedade, pois daí advêm vantagens (E IV P 35 Esc p. 305). Entretanto, como sabem disso e por que vivem em sociedade, já que são, essencialmente, desejos em conflito?

O parágrafo 13 do capítulo II do TP parece se fundar nisso que se pode chamar de convenientia ou 'astúcia da razão', ou seja, a razão que, subrepticiamente, se serve da esperança "[...] para dar força operante à potência racional das noções comuns." (CHAUI, 2011, p. 182).

Dessa maneira, como dois se põem de acordo e juntam forças? A esperança de uma potência maior, que faz que dois se juntem e possam mais, se funda nesta convenientia operando na natureza, a qual explicita um acordo que não se mostra em todas as suas facetas, mas indiretamente, por meio de um afeto alegre, a esperança. Esse é - eis uma hipótese - um pano de fundo constituído pela astúcia da razão, a qual, no plano afetivo, se 
apresenta por meio da emulação, por parte de vários homens, dos afetos medo-esperança, culminando na cessão de potência a uma instância responsável por criar e manter a civitas, ou seja, o poder soberano, do qual emana o direito civil.

Por outras palavras, os homens imitam, por emulação, a esperança uns dos outros para se unirem e buscarem os benefícios, a utilidade dessa união. Quando isto se tornar tão complexo a ponto de se necessitar de uma instância detentora da potência da cidade (o poder soberano), o par esperança-medo continua operando e sustentando, pela via da emulação, a potência deste poder, ao qual se deu o poder de editar leis. Tais leis são respeitadas pelo medo da punição e na esperança de se ter paz e não guerra, de se viver uma vida digna, ou seja, com potência individual tendente ao máximo, com alegria como afeto predominante. E ainda mais: o par afetivo medo-esperança será transmutado, pelas instituições da cidade, em segurança (securitas), afeto mais estável e garantidor do exercício dos direitos naturais individuais na civitas. $\mathrm{Na}$ verdade, o afeto esperança se transmuta em segurança na medida em que a cidade, por meio do funcionamento das instituições que o poder soberano cria, é capaz de diminuir a dúvida, nos cidadãos-súditos, quanto ao futuro. A cidade dever ser capaz de forjar este imaginário de segurança, o qual deve estar sempre presente nas mentes dos membros da cidade como uma espécie de futuroantecipado-em-forma-de-imagem-de-segurança. Somente instituições políticas da civitas são capazes de gerar tal imaginário de alegria em cada membro do corpo político, imaginário este que retroalimenta a própria força da cidade.

Porém, do ponto de vista da lógica dos afetos como emanação de uma conveniência (convenientia), própria da natureza, como se dá esta união de dois ou mais homens que devém multidão? A conveniência, espécie de razão com ' $r$ ' minúsculo (em contraposição a uma razão do acordo pleno - o agir em plenitude em acordo com a razão, o que acarretaria o fim do desacordo entre os desejos (E IV P 35 Cor 1 p. 303)), faz que os homens imitem os afetos uns dos outros no sentido da esperança comum e da segurança comum. Isto é, a mesma esperança que um homem sente ao se unir a um segundo é sentida por este segundo, simultaneamente, e assim sucessivamente, de modo que se tem um comportamento em bloco fundado num mesmo afeto, como num jogo de espelhos em que o comportamento de um é o mesmo do outro em razão da imitação afetiva. O mesmo se processa quanto ao afeto segurança, ainda mais estável e objetivo último da cidade. Apenas assim se pode explicar como funciona o que Espinosa expôs na passagem citada, ou seja, "Se dois se põe de acordo e juntam forças [si duo simul conveniant et vires jungant (G III p.281)], juntos podem mais [...]; e quanto mais assim estreitarem relações, mais direito terão todos juntos." (TP II 13 p. 18). O convir é sempre uma manifestação da razão, pois apenas pela razão os homens entram em acordo (E IV P 35 Cor 1 p. 303), ainda que por 
vias afetivas, pois o fundamento, aqui, é a emulação da esperança e da segurança do outro, uma forma, também, de conveniência. Conveniência talvez mais fraca do que se os homens se guiassem sempre pela razão, mas conveniência ainda assim. No texto latino, pela edição de Gebhardt, como se vê acima, há a ideia da simultaneidade e da conveniência (simul conveniant). O convir - esta 'astúcia da razão' ou razão de fundo - se dá pelo comum, pelo que une, ainda que por vias afetivas - e em geral por vias afetivas -, por uma espécie de regramento ou lógica que atravessa a natureza e a natureza humana. Uma conveniência, no sentido de uma lógica de operação da natureza mesma, que funda a imitação, via emulação, dos afetos esperança e segurança e, de outro lado, a emulação do medo da lei. Tais afetos, espelhados em múltiplos homens por emulação afetiva, levam ao comportamento que Espinosa designará pelo termo "[...] como que por uma só mente [una veluti mente ducuntur]." (TP II 16 p. 19). Não por acaso, portanto, escreve, no final do parágrafo 7 do capítulo III do Político, que "[...] esta união de ânimos [animorum unio G III p. 287] não pode de maneira alguma conceber-se, a não ser que a cidade se oriente maximamente [maxime intendat - G III p. 287] para o que a sã razão ensina ser útil a todos os homens." (TP III 7 p. 29). Espinosa não estabelece, aqui, que a cidade é fundada na razão, mas aponta para a pertinência da hipótese da 'astúcia da razão' (como o que emana do comum) ao afirmar que a união de ânimos, típica da multidão, não teria sentido se a cidade não se orientasse - isto é, não fosse 'no sentido de' - para o útil ensinado pela razão. Há, portanto, uma conveniência ou razão de fundo que fundamenta a concórdia via afetos alegres, ou pela via de afetos tristes que possibilitam afetos alegres, como é o caso do medo civil da punição da lei que faz que haja um mínimo de obediência às leis editadas pelo poder soberano e assim se chegue a um afeto alegre estável, a saber, a segurança. A convenientia é, nesse caso, também uma astúcia da política. Isto é, apenas a política é capaz de transmutar o medo da lei, afeto triste, em securitas, afeto alegre.

O que é, então, a multidão, a qual transfere potência ao poder soberano e lhe dá vida e potência? A multidão é a potência da multiplicidade dos desejos (sob a forma de esperanças e receios) articulados pelo que têm em comum, via emulação afetiva (AURÉLIO, 2000, p. 275).

Espinosa afirma que o direito definido pela potência da multidão costuma ser chamado de imperium (TP II 17 p. 20). Este ponto é retomado no capítulo 3 do Político para que a questão dos regimes seja colocada pela chave da distribuição da potência (BOVE, 2012, p. 17). Escreve Espinosa logo no início do referido capítulo (TP III 1 p. 25):

Diz-se civil a situação de qualquer estado [imperii cujuscunque status dicitur civilis G III 284]; mas ao corpo inteiro do estado [imperii] chama-se cidade, e aos assuntos comuns do estado [et communia imperii negotia G III 284], que dependem da direção de quem o detém, chama-se república. Depois, 
chamamos cidadãos aos homens na medida em que, pelo direito civil, gozam de todas as comodidades da cidade, e súditos na medida em que têm de submeter-se às instituições ou leis da cidade.

Os conceitos explicitados neste excerto foram analisados acima à luz da questão da imitação dos afetos, mostrando como a lógica do estar sui juris ou alterius juris tem estreita relação tanto com a lei do mal menor e do bem maior, quanto com a imitação da esperança e do temor alheios, pela via da emulação afetiva. O conceito de multidão demanda os conceitos de jus e de imitatio afetiva. Ocorre que tais conceitos deságuam nos gêneros de estado civil, passagem que vem logo a seguir à acima citada. Escreve Espinosa, após o excerto citado, agora derivando daqueles conceitos o dos gêneros de estado (TP III 1 p. 25):

Finalmente, dão-se três gêneros do estado civil [Denique status civilis tria dari genera G III p. 284], a saber, o democrático, o aristocrático e o monárquico [...]. Agora, antes de começar a tratar de cada um deles em separado, demonstrarei primeiro aquelas coisas que pertencem ao estado civil em geral, à cabeça das quais vem o direito soberano da cidade, ou dos poderes soberanos.

Espinosa dedicará, a seguir, alguns capítulos do Político à análise do estado monárquico, bem como outros à análise do estado aristocrático. Detalhará, igualmente, o modo de funcionamento de cada um desses gêneros de estado no sentido de mostrar como eles devem se constituir e se manter de maneira que sejam mais estáveis e garantam da melhor maneira o direito natural dos súditos. No mesmo sentido, detalhará as instituições aptas a cada um dos tipos de estado civil, e quais as que melhor operam, bem como a maneira de funcionamento de cada instituição em função do regime em que está em operação. Não se analisará o detalhamento das regras que Espinosa estabelece para que cada regime melhor funcione. Apenas no que se refere ao regime democrático será feita uma análise que tangenciará a questão das instituições. Isso porque interessa ao presente artigo, antes, mostrar como a questão da potência e dos afetos da multidão acaba sendo o que há de substrato ou fundamento para qualquer dos regimes. Este o ponto que será desdobrado a seguir.

À questão dos regimes, pois. O último capítulo do Tratado político, dedicado ao regime democrático, restou incompleto (reliqua desiderantur o resto falta - G III p. 306; TP XI 4 p. 140). Espinosa faleceu antes de completá-lo. Entretanto, algumas considerações acerca desse tipo de estado poderão ajudar a esclarecer como a questão da distribuição da potência está na base dos raciocínios da filosofia política espinosana para a definição dos gêneros de estado civil. 
Procurou-se mostrar, nos itens acima, que o poder do soberano - ou direito do imperium - é o direito de natureza expresso, ou seja, determinado, pela potência da multidão, conforme Espinosa indica no Político (TP III 2 p. 25). Ao fazê-lo, procurou-se explicitar a presença da lógica dos afetos, assim como de sua imitação, para a constituição da multitudo e para que esta transfira potência ao poder soberano e o mantenha, bem como, consequentemente, mantenha o imperium.

Porém, Espinosa fala, ainda assim, em gêneros do estado civil. O que os caracteriza e os define, dada a lógica afetiva e de potência na confecção do imperium? Espinosa indica três gêneros do estado civil: o democrático, o aristocrático e o monárquico (TP II 17 p. 20; TP III 1 p. 25). Afirma, também, que a potência da multidão, que define o direito, chama-se imperium (TP II 17 p. 20). Isto se dá pela lógica dos afetos, na hipótese deste artigo. Quem detém este direito por completo, absolutamente? Aquele que, por consenso comum (communi consensu G III p. 282), tem a incumbência da república (curam reipublicae ex communi consensu habet $\mathrm{G}$ III 282), que é a de estatuir, interpretar, abolir direitos, etc.. E o que define o tipo de estado? Espinosa afirma que é precisamente aquele ou o quê fica com a incumbência da república que define o tipo de imperium.

Se a incumbência da república pertencer a um conselho que é composto pela multidão comum (communi multitudine componitur G III p. 282), o estado é democrático. Se o conselho for composto por alguns eleitos, trata-se de aristocracia. Se o imperium, isto é, a incumbência da república, estiver nas mãos de um, o estado é monárquico. Portanto, ao que indicam os textos, os critérios dos tipos de estado civil em Espinosa apenas formalmente passam pela questão do número de governantes. Por outro lado, não se duvida que a questão do número dos que detêm o poder de dizer o direito importa. E o prova o fato de que Espinosa se refere aos números, à quantidade - todos, alguns, um - dos que têm a incumbência da república ao tratar dos gêneros de estado civil, como mostrado no Político (TP II 17 p. 20). Mas o que sustentará a potência do imperium não é o número dos que têm a incumbência da república, mas a potência da multidão. $\mathrm{O}$ que de fato sustentará a potência da cidade, por meio da potência da multidão, é o acesso dessa potência aos conselhos ou ao conselho supremo - no caso da existência de outros conselhos.

Assim, se todos têm acesso ao conselho, se todos podem vir a fazer parte dele (ou seja, os membros da multidão comum), tem-se por conseguinte a democracia. A democracia não parece ser, pois, o governo de todos simplesmente. Ela está mais próxima de ser, ao que indicam os textos, a possibilidade de todos virem a compor o conselho, segundo regras instituídas de acesso a este mesmo conselho. Em outras palavras, as regras de acesso ao conselho, num estado democrático, possibilitam que todos que compõem a multidão comum, segundo regras de idade ou pertencimento à cidade, venham a tomar parte dele e venham a exercer o poder soberano, 
que tem a incumbência da república. E a potência desse conselho será, assim, a expressão da potência da multidão comum.

No Teológico-político, Espinosa afirmara que o que caracteriza o regime democrático é a sociedade instituída sem contradição com o direito natural (TTP XVI p. 239). Ou seja, cada indivíduo deve "[...] transferir para a sociedade toda a sua própria potência, de forma que só aquela detenha, sobre tudo e todos, o supremo direito de natureza, isto é, a soberania suprema, à qual todos terão de obedecer, ou livremente, ou por receio da pena capital." (TTP XVI pp. 239-240). E conclui: "O direito de uma sociedade assim chama-se Democracia, a qual, por isso mesmo, se define como a união de um conjunto de homens que detêm colegialmente o pleno direito a tudo que estiver em seu poder." (TTP XVI p. 240). Mais à frente, Espinosa concluirá que a democracia é o regime mais natural, o que mais se aproxima da liberdade que a natureza reconhece a cada um (TTP XVI p. 242).

As instituições que seriam as mais adequadas a este tipo de estado civil certamente Espinosa desdobraria no Político, a obra inacabada. É o que indica o projeto apresentado na Ep.84, reproduzido pelos editores das $O P$ (Opera Posthuma) como prefácio ao Político (TP Pref p. 3). Mas talvez algumas hipóteses possam ser levantadas a partir do que há no capítulo XI do TP. O que significa, pois, nesse sentido, dizer que o conselho é composto pela multidão comum? O que seria a democracia para o TP?

Inicialmente cabe afirmar que a hipótese deste artigo é a de que não há aqui contradição entre as teses do Teológico-político, em seu capítulo XVI, em momento acima citado, quando é tratada a democracia, e o Político. Quando Espinosa escreve, no Teológico-político, que a democracia é o regime o que mais se aproxima da liberdade que a natureza reconhece a cada um (TTP XVI p. 242), trata-se da natureza de conatus de cada homem como parte da natureza, como intensidade de potência $d a$ e na sustância única. Ou seja, entende Espinosa, nesta passagem, cada homem como potência para perseverar no ser, tese decorrente da ontologia espinosana e de sua noção de substância como potência e dos homens como modos finitos de intensidade dessa mesma potência. E é claro que na democracia, na medida em que um maior número de homens detém colegialmente o direito a tudo (TTP XVI p. 240), um maior número será o responsável, como potência, pelas regras que todos deverão obedecer. Em uma palavra, o maior número poderá compor a instância instituidora do direito (das leis civis) que todos deverão obedecer. Nesse sentido a democracia, no Teológico-político, é definida como o regime mais natural. É uma questão de potência do maior número definindo quais serão as regras para todos. Daí que seja o regime que mais se aproxima do estado de natureza e do direito de natureza de cada homem. Não, entretanto, no sentido do direito natural como abstração (TP II 15 p. 19), mas no sentido de exercício da potência natural, via poder soberano, na medida em que o maior número pode ocupar tal poder e 
instituir as regras comuns - ter as incumbências da república. Assim se está mais próximo da natureza humana no sentido de que cada homem quer governar e não ser governado. Na democracia, esta máxima, decorrente da natureza humana - querer governar e não ser governado -, mais se aproxima de sua realização, pois o maior número decide as regras que serão aplicadas a todos.

No Tratado político talvez se tenha apenas maior clareza quando ao modo como isto se instrumenta no regime democrático. Que se trata de questão de potência da multidão na definição de qualquer regime uma passagem da análise espinosana da monarquia deixa claro. É a seguinte (TP VII 31 p. 85): "Concluímos, assim, que a multidão pode conservar sob um rei uma liberdade bastante ampla, desde que consiga que a potência do rei seja determinada somente pela potência da mesma multidão e mantida sob a guarda desta." Mas a conclusão é ainda mais clara acerca do critério da potência da multidão como sendo o critério do regime do estado civil (TP VII 31 p. 85): "Foi esta a única regra que segui ao lançar os fundamentos do estado monárquico".

De volta à democracia. Que se a analise sob a ótica do último capítulo do Tratado político. Ao que indicam os parágrafos restantes (quatro), são vários os gêneros possíveis de estado democrático, segundo Espinosa (TP XI 3 p. 138). Mas todos parecem passar pelo critério de que os membros da multidão comum, segundo regras aceitas por ela mesma, possam ou não participar do conselho supremo e ter acesso a cargos públicos na cidade. É o que diz Espinosa no parágrafo 1 do capítulo XI. De fato, afirma Espinosa, todos cujos pais sejam cidadãos, ou que tenham nascido no solo pátrio, ou que são beneméritos da república, ou aqueles a quem a lei, por outros motivos, manda atribuir o direito de cidade, poderão ter "[...] o direito de voto no conselho supremo e de aceder por direito a cargos de estado [...]." (TP XI 1 p. 137). Ou seja, ao que indica o texto, o critério inicial é o de poder votar no conselho supremo e o de poder ter acesso a cargos do imperium. A questão é quem pode ter acesso a estas ações e cargos. Como dissera o parágrafo 17 do capítulo II, a democracia se caracteriza por ter um conselho cuja composição é feita pela multidão comum. O capítulo XI apenas indica que as regras para que essa participação ocorra podem ser várias - ter pais cidadãos, nascer em solo pátrio, etc.. Em suma, o critério é institucional.

Mas a questão da potência logo aparece no texto no parágrafo 3 do capítulo XI. Espinosa lá escreve que não tratará de cada um dos gêneros, mas apenas daquele onde têm direito de voto e de aceder a cargos do imperium os que estão obrigados somente às leis da cidade e aqueles que estão sui juris. Ora, estar sui juris é o mesmo que ter direito e potência, não estar sob o poder de outrem. O primeiro critério mostra que se quer dar ao conselho potência de quem pertence ao imperium. Se ele é a potência da cidade, deve ter potência para fazer leis que tenham potência. Portanto, o 
conselho perderia em potência caso fosse formado por membros estrangeiros. Ainda, há outro critério: estar sui juris. Isto exclui, segundo Espinosa, mulheres e servos, que estão sob o direito dos homens e dos senhores, respectivamente.

Independentemente da questão polêmica da exclusão das mulheres ${ }^{6}$ da possibilidade de compor o conselho que definirá a potência da cidade, pois definirá suas leis, o que parece ser comum é a exclusão da possibilidade de participação daqueles que não podem levar potência ao conselho, o que poderia indicar diminuição da potência do conselho e, consequentemente, do poder soberano.

$O$ ponto que interessa ressaltar, na esteira do que vem sendo afirmado sobre a filosofia política de Espinosa até o momento, mas agora para tratar espinosanamente da questão dos tipos de estado civil, é que o critério definidor do tipo de estado civil, segundo Espinosa, se funda na ontologia, o que liga a política ao livro I da Ética. Tanto o estado monárquico quanto o estado democrático - as duas pontas da linha de distribuição da potência da multidão no conselho supremo -, passando pelo aristocrático, se fundam na potência de seus membros, isto é, dos componentes do conselho cujos membros têm a potência definida pela multitudo mesma. No regime monárquico, com efeito, Espinosa define como critério de seu bom funcionamento, de sua estabilidade, a potência do rei ser fundada e mantida pela potência da multidão (TP VI 31 p. 85). No estado civil democrático, no mesmo sentido, o critério para votar no conselho e aceder a cargos do imperium, ao menos segundo o Político de modo explícito (TP XI 3 pp. 138-139), passa pelo conceito de potência dos que serão membros. De fato, só pode votar e aceder a cargos públicos quem está sui juris - excluindo-se servos, filhos, pupilos e mulheres, todos sob o

${ }^{6}$ Pode-se verificar que a questão das mulheres na democracia está posta muito laconicamente no capítulo XI do Político. Isso porque Espinosa, provavelmente, não teve tempo de desdobrar a questão em itens subsequentes, uma vez que faleceu antes de completar o texto do Político. Numa leitura literal, sem refinamentos e cotejo com as demais obras, Espinosa parece realmente excluir, por natureza, as mulheres do governo democrático. Mas esta afirmação coloca o Espinosa do final do Político em contradição com o Espinosa da Ética e do Teológico-político. Parece que a tese da exclusão pura e simples das mulheres realmente não se coaduna com o restante da obra do autor. Para um estudo clássico acerca do tema, ver MATHERON, 2011, p. 287-304. Ver também (CHAUI, 2013) Na ocasião, a autora analisou a questão das mulheres no Político. A posição da autora pode ser resumida na seguinte passagem do texto lido na ocasião: Espinosa exclui as mulheres por natureza, não por instituição. Mas se fosse a natureza das mulheres, Espinosa estaria em contradição consigo mesmo, visto que na Ética homens e mulheres são desejo para perseverar no ser. Não há diferença ontológica. Então afirma: "É, portanto, a paixão libidinosa masculina a causa natural da fraqueza das mulheres na política. A naturalidade da fraqueza ou a afirmação de que ela não é produto da instituição não se refere à natureza feminina e sim à forma natural da relação passional que os homens estabelecem com as mulheres" (grifos da autora, p. 20). Isto é, as mulheres levariam a cidade à instabilidade uma vez que a relação dos homens com elas não leva em conta a prudência ou outra característica das mulheres, mas o afeto libidinoso. 
argumento de que não estariam sui juris. Ou seja, o critério é sempre o da potência, e assim os fios da ontologia da Ética I, dos afetos da Ética III e dos conceitos políticos do Teológico-político e do Político permanecem atados.

A questão dos regimes políticos ou dos gêneros do estado civil, em Espinosa, pode-se concluir, demanda a compreensão dos conceitos inovadores por ele propostos. Em suma, não se pode compreender os regimes sem que se analise a questão da potência e da multidão. Sem tais conceitos, o problema do número dos que governam é ficção vazia, que nada explica. Talvez aí um novíssima lição desse clássico do dezessete: sem a potência da multidão dando potência ao poder soberano, e este espraiando afetos alegres pela cidade, nenhum regime político se sustenta. A indignação da multidão pode derrubar o poder soberano, seja ele composto pelo monarca e seu séquito, seja ele composto pelos eleitos ao conselho supremo no regime democrático. De fato, a fonte última e primeira da potência do Estado é a multidão, união de desejos dispersos por meio da imitação afetiva. Lição para tempos atuais. 


\section{Referências bibliográficas}

AURÉLIO, Diogo Pires. "Introdução". In: ESPINOSA. Tratado político. São Paulo: Martins Fontes, 2009.

- Imaginação e poder: Estudo sobre a Filosofia Política de Espinosa. Lisboa: edições Colibri, 2000, p. 334.

BOVE, Laurent. La stratégie du conatus. Paris: J. Vrin, 2012.

CAMPOS, André Santos. Ius sive potentia. Individuação jurídico-política na filosofia de Spinoza. Tese (doutorado). Departamento de Filosofia da Faculdade de Letras da Universidade de Lisboa. Lisboa, 2008.

CHAUI, M. "Medo e esperança, guerra e paz". In: Desejo, paixão e ação na ética de Espinosa. São Paulo: Cia das Letras, 2011, pp. 173-191.

Seminário Tratado político X e XI. Reunião do Grupo de Estudos Espinosanos na FFLCH USP. São Paulo, 25 de junho de 2013 (mimeo).

ESPINOSA. Spinoza Opera. Ed. de Carl Gebhardt. Heidelberg: Carl Winter, 4 vols, 1972 [1 $1^{\text {a }}$ ed. 1925]

2008.

Ética. Tradução de Tomaz Tadeu. Belo Horizonte: Autêntica,

. Tratado político. Tradução de Diogo Pires Aurélio. São Paulo: M.

Fontes, 2009.

Tratado teológico-político. Tradução, introdução e notas de Diogo Pires Aurélio. São Paulo: Martins Fontes, 2003.

MATHERON, Alexandre. "Femmes et serviteurs dans La démocratie spinoziste". In: Études sur Spinoza et lês philosophies de l'âge classique. Lyon: ENS Éditions, 2011, pp. 287-304.

MONTANS BRAGA, Luiz Carlos. Trama afetiva da política: uma leitura da filosofia de Espinosa. Tese de doutorado. PUC SP. 2015. Disponível em: https://www.sapientia.pucsp.br/bitstream/handle/11695/1/Luiz\%20Carlos\% 20Montans\%20Braga.pdf. Acesso em: 08 AGO 2016.

Autor(a) para correspondência: Luiz Carlos Montans Braga, Pontifícia Universidade Católica de São Paulo, R. Monte Alegre, 984, Perdizes, CEP 05014-901, São Paulo - SP, Brasil. montansbraga@ hotmail.com 